

\title{
The Time Trade-Off Method: an exploratory study
}

\author{
Anne Spencer ${ }^{*}$ \\ Department of Economics, \\ Queen Mary, University of London
}

October 2001

\begin{abstract}
In a pilot study we investigate whether the inferences we draw about people's preferences towards health care treatments are altered if we vary the procedure that is used to elicit these preferences. In a conventional Time Trade-Off question, respondents express their preferences towards treatment by comparing a period of ill-health with a shorter period in a higher quality of life. In our less conventional TTO question, we vary the procedure by asking respondents their preferences towards treatment by comparing a period of ill-health with a longer period in a lower quality of life. The quantitative data is equivocal about whether preferences for treatment differ between the conventional and unconventional questions. The qualitative data support the notion of contrasting issues in questions that involve prolonging time in a more severe quality of life and appear to account for a failure to find quantitative differences in all of the questions.
\end{abstract}

\section{JEL classification: $\mathrm{I} 31$}

Key words: Time Trade-Off; Procedural invariance

\footnotetext{
* Department of Economics, Queen Mary, University of London, Mile End Road, London, E1 4NS. Tel: 020-7882-5532; Fax: 020-8983-3580; e-mail address: a.e.spencer@qmw.ac.uk. I would like to thank Graham Loomes, Karl Claxton, Judith Covey, Nick Pidgeon and Carl Hampus Lyttkens for their valuable comments. In addition I am grateful for Lund University for funding a research fellowship to pilot the approach and ESRC money to finance a UK study. Any errors are solely mine.
} 


\section{Introduction}

In health economics, survey methods have been developed over the last thirty years to elicit people's preferences for undergoing different health care treatments. One of these methods is the Time TradeOff (TTO) method (Torrance, 1972). The aim of this paper is to test the equivalence of preferences elicited under the TTO method. A secondary aim of the paper is to consider the issues that respondents may be using to make their decisions.

The TTO method applies the principle of opportunity cost to different types of treatment by asking respondents to consider a trade-off between time and quality of life. In a conventional TTO method, preferences are elicited by asking the respondent to consider the point at which a shorter period in a higher quality of life is the same as an alternative offering a longer period in a lower quality of life.

It is quite possible that we are observing the beginnings of a trend to apply the TTO method in more unconventional ways. The interest in more unconventional TTO questions follows a line of research that attempts to make survey methods similar to the types of decisions that are sometimes considered by members of the general public, patients or policy makers (Beattie, Chilton, Cookson, Hopkins, Jones-Lee, Loomes et al., 1998). The particular unconventional procedure we consider is one that involves prolonging time in a lower quality of life. The possibility of prolonging time in a lower quality of health already occurs in the treatment for certain cancers. Jansen et al. have also raised an interest in such questions in applied work but as far as we are aware such questions have not been used (Jansen, Stiggelbout, Wakker, Vlieland, Leer, Nooy, 1998).

Pliskin, Shepard and Weinstein (1980) outline the assumptions required for the TTO method to be a valid measure of preferences under expected utility theory. One of the implications of expected utility 
theory is that preferences should be equivalent when elicited under the same method. If preferences are equivalent then the method is said to comply with procedural invariance (Tversky, Sattah and Slovic, 1988). Few papers have been published on procedural invariance for the TTO method - our paper addresses this gap. We do not advocate the unconventional TTO procedure over and above more conventional TTO methods but rather focus on the consistency of the responses between the conventional and unconventional methods. If the TTO method is consistent, and errors are small, the conventional TTO questions should be consistent with the values derived under these more unconventional TTO methods.

Concern over whether procedural invariance holds in practice has already been expressed for preference elicitation methods that involve a trade-off between quality of life on the one hand and either risk or money on the other (Beattie, Covey, Dolan, Hopkins, Jones-Lee, Loomes et al., 1998). In the Standard Gamble (SG) method that involves risk, it has been shown that under certain conditions procedural invariance systematically breaks down (Chilton and Spencer 2001, Llewellyn-Thomas, Sutherland, Tibshirani, Ciampi, Till and Boyd, 1982). In the Contingent Valuation (CV) method that involves money, the difference between asking the question in terms of a person's willingness-to-pay or willingness-to-accept money is well documented (Beattie, Chilton, Cookson, Covey, Hopkins, Jones-Lee, et al., 1998). In the SG and CV methods this has lead to the development and application of alternatives to expected utility theory to explain the systematic failures of procedural invariance. We add to this debate by exploring the possible explanations of our TTO findings.

The paper uses a combined qualitative and quantitative approach to reveal the issues considered by respondents in their answers. There appears to be renewed interest in linking qualitative and quantitative approaches in the field of value elicitation to help understand the issues driving respondents' answers. However, there have been relatively few joint qualitative and quantitative studies of value elicitation procedures (Dolan and Cookson 2000; Dolan, Cookson and Ferguson 1999; 
Dolan and Green 1998; Robinson, Dolan and Williams 1997). An advantage of collecting qualitative data alongside quantitative data is that where anomalies fail to manifest themselves at the aggregate level, even if expected, the qualitative data can help identify possible contrasting issues that would help to explain this result. A qualitative and quantitative approach is particularly applicable in this paper given the pilot nature of this work and that the quantitative analysis is equivocal.

\section{Method}

\subsection{Overview of the questionnaire}

The study used the EuroQol classification system, which describe states of health along five dimensions: mobility, self-care, usual activities, pain and anxiety. Each dimension has three levels of severity: no problems, some problems and more severe problems, denoted by 1, 2 and 3 respectively and colour-coded black, blue and red in our study. Respondents were asked to tick one statement from each dimension that best described their current state of health. This helped to familiarise respondents with the EuroQol dimensions. Respondents were then presented with 6 cards: 5 EuroQol states (11111, 12221, 21211, 21222 and 22232) and immediate death. Other studies had shown that these states gave distinct mean and medians and were chosen to ensure that respondents could easily discriminate between the different states (Dolan, 1996). Each state was colour-coded: 11111 was given the colour white, 12221 the colour grey, 21211 the colour yellow, 21222 the colour green, 22232 the colour pink and death the colour black. These are referred to here by letters: 11111 is referred to as $\mathrm{N}, 12221$ as W, 21211 as $\mathrm{X}, 21222$ as $\mathrm{Y}, 22232$ as Z and death as D. The state 12221 was used to allow respondents to become familiar with the methods but the actual values were not used in the study. The tests relied on the states being better than death. 
The respondents were asked to imagine that each state lasted for ten years without change, to be followed immediately by death. They were asked to rank the cards from the best state to the worst and then to place the cards on a visual analogue scale, putting the best state at 100 and the worst state at 0 . This was followed by 12 TTO questions, then 7 SG questions. The research question posed in this paper involves the TTO questions only and the SG questions are reported elsewhere. To elicit the preferences we used the TTO boards and interview protocol developed by the measurement and valuation of health study (Gudex, Dolan, Kind and Williams, 1997). These boards and interview protocols were modified slightly to include the colours depicting each health state and to allow for the new types of TTO questions presented here. The respondents were asked 4 conventional TTO questions that valued health states against normal health and death (questions 1 to 4). They were then asked 8 more TTO questions. We concentrate here on the two TTO questions that involved prolonging time in a lower quality of life (questions 9 to 10) and the remainder of the TTO are reported elsewhere. These TTO questions considered here fall into three broad categories (using the question number used during the questionnaire):

Questions 1 to 4 . Conventional TTO questions: valuing a health state against normal health and death.

Questions 9 and 10. Unconventional TTO: valuing a health state against worse health state (and one that is ranked lower than the health state being valued).

In questions 1 to 4 , respondents were asked to imagine living in a given health state for 10 years or a treatment which offered them a combination of time in a better state and time in a worse state. In questions 9 and 10, respondents were asked to imagine living in a given health state for 2 years followed by death, or prolonging life in a lower quality of life. Throughout we will adopt the convention that direct values refer to the values implied by direct comparisons with normal health and 
death and indirect values refer to values implied by questions that involve prolonging time in a lower quality of life.

Table 1. An overview of the questionnaire

\subsection{TTO questions}

\subsubsection{Conventional TTO questions}

The respondents were asked 4 conventional TTO questions that valued health states against normal health and death (questions 1-4 in table 1). These questions were used to assign a value for each health state based on a direct comparison with normal health and death and were used to check the consistency of later responses.

These conventional TTO questions are illustrated using question 3 in figure 1. A respondent was asked to imagine living in health state $\mathrm{Y}$ for 10 years or undergoing a combination of $\mathrm{t}_{3}$ years in normal health $\left(\mathrm{N}\right.$ ) but dying (D) 10- $\mathrm{t}_{3}$ years earlier (where the subscript on the time, $t$, indicates the question number). In effect, they were asked to consider a shorter period in a higher quality of life.

Figure 1. Question 3

The time in normal health $t_{3}$ was varied until the respondent was indifferent between the two alternatives. At this point the two alternatives should be equivalent. The majority of applied work using the TTO method then assumes that respondents do not have preferences towards the timing of ill-health (or a zero rate of time preference), Dolan 2000. It is therefore possible to express this equivalence by the following equality where V(.) represents the TTO value assigned to the health state: 
$10 \quad \mathrm{~V}(\mathrm{Y})=\mathrm{t}_{3} \quad \mathrm{~V}(\mathrm{~N})+\left(10-\mathrm{t}_{3}\right) \quad \mathrm{V}(\mathrm{D})$

If the value for $V(N)=1$ and $V(D)=0$ this expression can be rearranged to give $\mathrm{V}(\mathrm{Y})=\mathrm{t}_{3} / 10$

Question 3 is summarised in row 3 of table 1, where 10 years in health state Y (column 2) is compared against Normal Health and Death (column 3), and is used to derive a direct value for Y (column 4).

\subsubsection{Unconventional TTO questions}

We consider if preferences are altered if respondents are asked to consider the point at which a longer period in a lower quality of life is the same as a treatment offering a shorter period in a lower higher quality of life. For instance, in a conventional TTO question a health state Y is usually valued by comparing it against two other health states, of which one is better than Y (ranked higher than Y) and the other is worse than $\mathrm{Y}$ (ranked lower); refer to these two other health states as $\mathrm{X}$ and death respectively. It is possible to invert this procedure by interchanging health state $\mathrm{Y}$ with health state $\mathrm{X}$ and ask respondents to value $\mathrm{X}$ against $\mathrm{Y}$ and death. Importantly, this implies that the respondent must be willing to prolong time in the more severe state $(\mathrm{Y})$ to reach a point of equivalence, since $\mathrm{X}$ is ranked higher than $\mathrm{Y}$.

This is illustrated by considering the conventional TTO question in figure 2 . In figure 2 respondents would be asked to value health state $\mathrm{Y}$ against health state $\mathrm{X}$ and death (D). This question can be inverted if the time in health state $\mathrm{X}$ is fixed, and the respondent is asked to consider prolonging time in a lower quality of life, health state $\mathrm{Y}$. This has the implication of prolonging life expectancy in a poorer health state as shown in figure 2 . 
Figure 2. Example and links with question 10

This was included in the questionnaire as question 10 . The time in health state $\mathrm{X}$ was set at 2 years since using previous studies it was anticipated that the responses to these questions would lie within a ten year period. The question then begins by comparing 2 years in health state $\mathrm{X}$ and 2 years in health state $\mathrm{Y}$ and respondents are asked which they prefer. When the time is the same, all respondents prefer to spend time in the higher quality of life, $\mathrm{X}$. The time is in the lower quality of life is then increased until they consider the alternatives to be most finely balanced and they do not mind which treatment they receive (the questionnaire and protocol are available upon request from the author). At this point of indifference between the two alternatives the following equality holds, assuming that respondents have a zero rate of time preference:

$2 \mathrm{~V}(\mathrm{X})=\mathrm{t}_{10} \mathrm{~V}(\mathrm{Y})$

If $\mathrm{V}(\mathrm{Y})$ is say, $\mathrm{V}(\mathrm{Y})=\mathrm{t}_{3} / 10$ (from question 3 ) this leads to:

$\mathrm{V}(\mathrm{X})=\frac{\mathrm{t}_{10} \mathrm{t}_{3}}{20}$

Question 10 is summarised in row 6 in table 1, where 2 years in health state $\mathrm{X}$ (column 2) is compared against a longer period in $\mathrm{Y}$ (column 3), and is used to derive an indirect value for $\mathrm{X}$ (column 4).

The null hypothesis to be tested using question 10 and the earlier conventional TTO question is that $\mathrm{H}_{0}$ : direct $\mathrm{V}(\mathrm{X})=$ indirect $\mathrm{V}(\mathrm{X})$ and the alternative hypothesis is $\mathrm{H}_{1}$ : direct $\mathrm{V}(\mathrm{X}) \neq$ indirect $\mathrm{V}(\mathrm{X})$. Similarly in question 9 we calculate the indirect value for $\mathrm{Y}$ and we test the null hypothesis that $\mathrm{H}_{0}$ : direct $\mathrm{V}(\mathrm{Y})=$ indirect $\mathrm{V}(\mathrm{Y})$ and the alternative hypothesis that $\mathrm{H}_{1}$ : $\operatorname{direct} \mathrm{V}(\mathrm{Y}) \neq$ indirect $\mathrm{V}(\mathrm{Y})$. 


\section{Data}

Respondents were recruited from members of the general public and from mature students beginning a course in the Department of Health Sciences at the University of York. Respondents were invited to take part in a 90-minute interview in the Department of Economics at York University for a payment of $£ 15$. All interviews were tape-recorded. In total, 30 respondents were interviewed, 12 males and 18 females.

Table 2. The sample

Respondents were recruited from people who were aged between 21 and 59. The study did not recruit people who were 60 years old or over as it was felt that they might imagine dying before the end of the 10 year period. This approach was similar to one taken by Miyamoto and Eraker (1988) who restricted the age of their sample to ensure that respondents would in principle be willing to trade time. In addition, it was felt that they had a mature outlook on issue of health and survival, and were more likely to have known friends and family who had been ill and would know how they would react to illhealth. Chapman (1996) raised the issue that a sample of students may find it hard to imagine states that they were likely to have had little experience.

In the qualitative data the respondent was asked to think aloud during the questions and to declare the types of information that they were heeding or concentrating using a verbal protocol analysis approach developed by Ericsson and Simons (1980). The study made use of clarification probes in one of two ways (Patton 1990). The interviewer verbalised a respondent's non-verbal cues, such as eye or hand 
movements which were used to emphasise a point. The interviews were transcribed and analysed using the software package HyperResearch ${ }^{\circledR}$ that aids the management and analysis of non-numerical data. This analysis produced 14 general codes and 133 specific codes.

\section{Results}

\subsection{Quantitative results}

The median values for health states $\mathrm{X}, \mathrm{Y}$ and $\mathrm{Z}$ are $0.9,0.65$ and 0.45 (see table 3 ) and the Wilcoxon signed ranks test showed that respondents found the states statistically different $(P=0.0002$ or less in all cases).

In the TTO questions that involved prolonging time in a lower quality of life (questions 9 and 10) the median value was higher for health state $X$, with an indirect value of 1.05 compared to a direct value of 0.90. However, this trend was less apparent for the median indirect value for health state Y, with an indirect value of 0.7 compared to a direct value of 0.65 . The Wilcoxon signed ranks test showed the indirect values for $\mathrm{X}$ were significantly higher than the values based on normal health and death (in question 10) whilst the differences between the indirect and direct values for Y were not statistically different, and responses were evenly spread between higher and lower indirect values (in question 9, column 1 rows 1 and 2 in table 4).

Table 3. The summary statistics

Table 4. The Wilcoxon signed ranks test 
In summary, the quantitative results were mixed: the indirect values for $\mathrm{X}$ were significantly higher in questions 10 than values based on normal health and death, but the indirect value for $\mathrm{Y}$ were not statistically different to values based on normal health and death in question 9. 


\subsection{Qualitative results}

In the qualitative analysis responses appeared to fall into 5 themes listed in tables 5 and 6 for questions 9 and 10 respectively. The first row of tables 5 and 6 refers to the number of respondents in questions 9 and 10 who were willing to trade quality for longevity of life (based on specific codes $Q 9$ trade-off and $Q 10$ trade-off). For example, in question 9 that asked respondent to consider prolonging time in the more severe health state (health state $\mathrm{Z}$ ), 13 of the 28 respondents expressed a willingness to trade quality for longevity of life. This willingness to trade rose to 21 respondents in question 10 that considered prolonging time in the more moderate health state (health state Y).

Table 5. The direct and indirect value for health state $\mathrm{Y}$

Table 6. The direct and indirect value for health state $\mathrm{X}$

The main reasons for their willingness to trade quality of life for longevity of life related to the impression that 2 years was too short (specific codes: $Q^{9} 2$ years short, $Q 102$ years too short, $Q^{9}$ that or death, Q9 yes alive, Q10 want extra life, Q10 still alive) and that they would need more time to achieve the same life goals (specific codes: $Q 9$ something to achieve, $Q 10$ a bit more). Respondents that were willing to trade account for the majority of the cases where the indirect value for a health state is greater than the direct value (column 2, tables 5 and 6).

Of those respondents who were willing to trade quality of life for longevity of life, some respondents felt that they would need more time in Z to compensate (specific codes: $Q^{9}$ increase by a lot, $Q^{9}$ need longer Z). This supports the notion that respondents sought longer periods of time to compensate for the reduction in the quality of life. In addition, they felt that they might accommodate to the health state (specific code: Q10 accommodate) or could cope with the state (specific code: Q10 cope). Other respondents felt that they wanted longer to live but disliked the more severe health state $\mathrm{Z}$ (specific 
codes: $Q 9$ try hold on, $Q 9$ only just cope, $Q 9$ hang on, $Q 9$ knock deaths door, $Q 10$ adding poor quality, Q10 not stand depression, Q10 plod, Q10 max endurance Y).

The second most popular response related to an unwillingness to prolong time in a lower quality of life (based on specific codes: Q9 2 not prolong and Q10 2 not prolong). In the case of questions that involved prolonging time in the more severe health state $\mathrm{Z}, 11$ of the 28 respondents were unwilling to prolong time in $\mathrm{Z}$ (row 2 table 5). An example of the unwillingness to prolong in a lower quality in $\mathrm{Z}$ given below:

Respondent : I wouldn't really want it, it's a because it's only 2 years anyway, but my sort of personal feeling looking at it right now is, that's it would be 2 years in pink (Z) or 20 years in pink (Z) there's not a great deal that's going to be accomplished, if I'm able to I'll see the kids grow up and that, so a definite choice that I would want to live, but I think that my own state of mind that I would go crazy in the end, so I'll stick with choice B. Interview 12, Q9 2 not prolong.

The main reasons for respondents' unwillingness to prolong time in a lower quality of life centred around the impression that this state represented a very severe state of health (specific codes: $Q^{9}$ absolute writhing, Q9 go crazy, $Q^{9}$ suffer, $Q^{9}$ seen people suffer, Q10 2 major categories, Q10 can take so much, Q10 prolong pain). However, all these respondents have considered health state $\mathrm{Z}$ to be better than death in the conventional TTO questions. Some respondents saw immediate death as an option to a lingering death in a lower quality of life (specific codes: $Q^{9}$ believe in euthanasia and $Q^{9}$ go quickly) whilst others just stated that they would receive no benefit from increasing time in a lower quality of life (specific codes: $Q^{9}$ no point and $Q^{9}$ not worth living).

There was an indication that more of the respondents would have been unwilling to prolong the time in the lower quality of life if the alternative with which they were initially presented was for longer than 2 
years (2 respondents, specific codes: Q9 2 years short and $Q 102$ years short). An examples of these types of responses is given:

Respondent: 2 years isn't long, but I'm not too bad am I, I don't know because it's a hard comparison to make because I don't want to be in pink (Z) at all, so the thought of being in pink (Z) for any length of time, fills me with dread but the thought of being in green (Y) for 2 years is equally as bad because it's only two years, so the instinct is to favour pink (Z) because it's for longer,.....

Interview 14, Q9 2 years short.

Some respondents were willing to increase the longevity of life irrespective of quality of life (based on specific codes: Q9 2 prolong because like life and Q10 prolong because like life; row 3 tables 5 and 6). In the case of questions that involved prolonging time in health state $\mathrm{Z}, 3$ of the 28 respondents were willing to prolong time irrespective of the quality of life (row 3 table 5). An example of these types of responses is given:

Respondent: No, I would always go for choice A, length of life rather than quality of life.

Interview 8, Q9 prolong life because like life.

The main reasons for increasing longevity of life irrespective of quality of life seemed to relate to the desire for longer lives and could relate to the fact that they only had 2 years to live $(Q 10$ can envisage 2 years).

These two types of responses, an unwillingness to prolong time in a lower quality of life and a willingness to increase longevity irrespective of quality of life, account for the majority of cases where the indirect values for the states were lower than those based on direct comparisons with normal health and death. For example, in question 9, 10 of the 11 respondents who were unwilling to prolong time in 
the lower quality of life gave an indirect value that was lower than the direct (row 2 column 2 table 5). This effect is greater for health state $\mathrm{Y}$ in question 9 than health state $\mathrm{X}$ in question 10 and is likely to account for our failure to find statistical differences between the direct and indirect value for Y.

\section{Discussion}

We are unable to conclusively reject procedural invariance, with only one of the two test detecting a statistical difference. In this section, we consider the possible explanations of our results.

Table 7 summarises 4 issues that are predicted to affect TTO responses which are: 1) a disproportionate concern for the quality of life; 2) time preference; 3) a disproportionate concern for the longevity of life; and 4) maximal endurable time. In the following discussion we outline the links between these 4 issues and the indirect value. We find that the first 2 issues would serve to increase the indirect value whilst the last 2 would serve to reduce the indirect value. The impacts that these issues have upon the indirect value are denoted in table 7 as: ' + ' for an increase in the indirect value relative to the direct and '-' a decrease. We conclude by considering whether these issues account for our findings.

Anomalies between the direct and indirect values may arise if respondents give disproportionate weight to quality of life or longevity of life in the elicitation of indirect values. For example, in question 9 , let $\mathrm{t}_{9}{ }^{\mathrm{e}}$ denote the time in $\mathrm{Z}$ under expected utility theory and $\mathrm{t}_{9}{ }^{\mathrm{q}}$ denote the time in $\mathrm{Z}$ under a disproportionate concern for quality of life. If a respondent demands a disproportionately larger increase in the time spent in the more severe state to compensate for the lower quality of life offered in the comparison treatment then $\mathrm{t}_{9}{ }^{\mathrm{q}}>\mathrm{t}_{9}{ }^{\mathrm{e}}$. The indirect value in this case, therefore, will be higher than the direct value. The quantitative results appear to support this with an indirect value that was higher than 
the direct value. Disproportionate concern for the quality of life was also in evidence in qualitative responses that sought a larger increase in time to compensate for the reduction in quality of life.

Table 7. Summary of predicted impacts

A respondent may instead have a disproportionate concern for the longevity of life in the elicitation of indirect values. For instance, in questions that involve prolonging life, they may seek to increase their length of life even if this puts them in a more severe health state. They would, therefore, be willing to take any treatment which offered a marginal increase in time. However, the same respondent may be unwilling to give up time in the elicitation of direct values. For example, in question 9 , let $t_{9}{ }^{1}$ denote the time in $\mathrm{Z}$ under a disproportionate concern for longevity of life. If a respondent prefers any treatment which extends life then $\mathrm{t}_{9}{ }^{1}<\mathrm{t}_{9}{ }^{\mathrm{e}}$. The indirect value in this case, therefore, will be lower than the direct values. Disproportionate concern for the longevity of life was in evidence in qualitative responses but was not sufficient to decrease the indirect value below the direct value.

If the health state is particularly severe a respondent may doubt their ability to cope with continuing illhealth, termed maximal endurable time by Sutherland et al. (1982). Sutherland et al. suggested that concerns over endurance may be particularly important if the health state is followed by death rather than normal health. Question 9 involved prolonging time in a more severe state Z, whilst question 10 involved prolonging time in a less severe state Y. We would, therefore, expect the maximal endurance to arise more in question 9 than question 10 . Let $\mathrm{t}_{9}{ }^{\mathrm{me}}$ denote the time in $\mathrm{Z}$ under maximal endurance in question 9. A respondent's fears that they cannot endure a severe health state may discourage some respondents from increasing time in the worse state and then $\mathrm{t}_{9}{ }^{\mathrm{me}}<\mathrm{t}_{9}{ }^{\mathrm{e}}$. The indirect value will then be higher than the direct value. The expectation that the maximal endurance affects question 9 more than question 10 appears to be borne out in our results. More than a third of the sample were unwilling to 
prolong time in a more severe health state $\mathrm{Z}$ in question 9 compared to only a tenth for prolonging time in health state $\mathrm{Y}$ in question 10 . The concern over the severity of $\mathrm{Z}$, therefore, appears to have undermined our ability to detect statistically significant differences in one of the two questions.

Finally, the TTO responses may be affected by a respondent's attitudes towards time. Like the majority of TTO applications, the present study assumes that a respondent does not have preferences towards the timing of ill-health (Dolan, 2000). It is as though a respondent gives equal weight to all time periods. If a respondent instead prefers to consume health in the short-term rather than in the long-term they will assign a higher weight to the short-term. A value that correctly adjusts for a respondent's time preference hereafter is termed a discounted value. The paper by Dolan and JonesLee (1997) can be used to show that the indirect value is higher than the discounted value, and the discounted value is in turn is higher than the direct value (see appendix). The net effect is the indirect value that is higher than the direct value and so can account for our findings.

There are two reasons to question whether time preferences alone are able to explain our findings. Firstly, Dolan and Jones-Lee (1997) show that the distortions related to time preferences are larger for health states that are valued around 0.5. The health states that are involved in question 9 are valued closer to 0.5 than those in question 10 , and so we would anticipate more of an impact in the former than the latter questions. The contrary result is found in our study. It is of course possible that in question 9 the concerns over the maximimal endurance undermined the impact of time preferences. Secondly, there is a general conclusion that although summary measures suggest people have no preference over the timing of ill-health, there is larger variation in preferences between people (Dolan and Gudex, 1995, Redelmeier and Heller, 1993). It is therefore, quite possible that incoporating people's preferences towards time into the values will lead to both higher and lower indirect values compared to the direct values, and so may fail to explain our findings. Nevertheless, information on a people's preferences towards the timing of ill-health would allow greater discrimination in the reasons 
for differences between the direct and indirect values and so is an important variable to consider in future studies.

The qualitative data help to shed light on the issues that people consider in their responses and suggests that two features can account for the quantitative results. Firstly, respondents who were willing to trade-off quality for longevity of life led to an indirect value that was higher than the direct value. The latter issue appears to be related to the disproportionate concern for quality of life, where respondents demand a disproportionately larger increase in the time spent in the more severe state to compensate for the decrease in the quality of life. It is also possible that people's preferences for the timing of illhealth led to an indirect value that was higher than the direct but we are unable to test for these effects separately here. Secondly, respondents who were unwilling to prolong time in a lower quality of life led to an indirect value that was lower than the direct value. The main driving force for such responses appeared to be related to maximal endurance and was stronger when respondents were asked to prolong time in the more severe state $Z$. The concern over the severity of $Z$, therefore, appears to have undermined our ability to detect statistically significant differences in one of the two questions. Hence, the quantitative results found higher indirect values for only one of the two questions considered.

It can be argued that an unwillingness to trade quality and length of life may be compounded by the short duration of the states in the TTO questions involving 2 years followed by death. Short time periods have been shown to affect people's willingness to trade in conventional TTO questions. McNeil (1981) found that, for states lasting under 5 years, patients with laryngeal cancer were unwilling to trade lengths of life for quality of life. However, unlike the questions here, the conventional TTO questions used by McNeil involved a reduction in length of life. The qualitative data allows us to reflect upon whether the short duration also affected our questions that increase the length of life. Some respondents explicitly stated that they would have been unwilling to prolong the time in the lower quality of life if the alternative with which they were initially presented was for 
longer than 2 years. A longer life span would therefore, lead to more cases where the indirect value is lower than the direct value. Disproportionate concern for longevity of life was evident in this study but could begin to dominate in longer time spans. We recommend further work to replicate the questions for different time periods.

In conclusion, for the TTO method that assumes people have no preference towards the timing of illhealth our study is equivocal about whether procedural invariance holds. The qualitative data raises some interesting issues despite the equivocal quantitative results. It provides some evidence that respondents give a disproportionate concern for the quality of life and this together with concerns over maximal endurance brings into question whether people make simple trade-offs between quality and longevity of life. A greater understanding of people's attitudes towards time appears a fruitful line of investigation. Other preference elicitation procedures are already exploring whether the calibration method, money or risk, affects responses. The Standard Gamble method that involves risk and Contingent Valuation method that involves money, are exploring respectively whether a respondent's attitudes towards risk or money follow the assumptions of expected utility theory or should be superseded by alternative decision making models (Rabin 2001; Chilton and Spencer 2001; Morrison 2000). Arguably a process of reflection has already begun in the TTO method, and is concentrated around modelling the preferences towards the timing of ill-health. There is a debate over whether to apply a constant proportional time preference model or a decreasing time aversion model (Cairns and van der Pol, 1997). There is also acknowledgement that preferences can be affected by the sequence of health states as well as the timing of ill-health (Gafni, 1995; Loewenstain and Prelec, 1993). Developments in these areas all contribute to our understanding of the issues considered by people in the TTO method. We should not lose sight, however, that the TTO procedures themselves may in some instances influence people's willingness to trade time. 


\section{Appendix}

Question 9 compares 2 years in $\mathrm{Y}$ and death or $\mathrm{t}_{9}$ years in $\mathrm{Z}$ and death. Question 9 therefore compares 2 years in $\mathrm{Y}$ and dying $\left(\mathrm{t}_{9}-2\right)$ years earlier or $\mathrm{t}_{9}$ years in health state $\mathrm{Z}$. Let a respondent's rate of time preference be represented by a discount weight, $\rho$, and let $0<\rho<1$. The discounted value for $\mathrm{Y}$ is then calculated from question 9 by equation (1).

$\sum_{0}^{1} \rho^{t} V(Y)=\sum_{0}^{t_{9}-1} \rho^{t} V(Z)$

where $t_{9} \geq 2$. The geometric progression formula is given as:

$\sum_{0}^{n-1} a \rho^{t}=\frac{a-a \rho^{n}}{1-\rho}$, using this in equation (1) to calculate the discounted value for $\mathrm{Y}$ :

$\frac{1-\rho^{2}}{1-\rho} V(Y)=\frac{1-\rho^{t_{9}}}{1-\rho} V(Z)$

Rearranging it follows that:

$\frac{V(Y)}{V(Z)}=\frac{1-\rho^{t_{9}}}{1-\rho^{2}}$

Given that $0<\rho<1$ it follows immediately that:

$\frac{V(Y)}{V(Z)}=\frac{1-\rho^{t_{9}}}{1-\rho^{2}}<\frac{t_{9}}{2}$

If we assume a zero rate of time preference in the indirect value then $\frac{V(Y)}{V(Z)}=\frac{t_{9}}{2}$, and so by equation (3) the indirect value overestimates the discounted value for $\mathrm{Y}$

The indirect $\mathrm{V}(\mathrm{Y})=\frac{t_{9}}{2} \mathrm{~V}(\mathrm{Z})$ calculated here, therefore, is higher than the discounted $\mathrm{V}(\mathrm{Y})=\frac{1-\rho^{t_{9}}}{1-\rho^{2}} \mathrm{~V}(\mathrm{Z})$

This effect is partly offset by any underestimation of the direct value $\mathrm{Z}$ which forms part of the indirect formula for Y (Dolan and Jones-Lee, 1997).

Dolan and Jones-Lee (1997) also showed that the discounted value is higher than the direct value in conventional TTO questions and so it follows that the indirect value for Y must also be higher than the direct value for $\mathrm{Y}$. 


\section{References}

Beattie, J., Chilton, S., Cookson, R., Covey, J., Hopkins, L., Jones-Lee, M., Loomes, G., Pidgeon, N., Robinson, A., Spencer, A. Valuing health and safety controls: a literature review, Contract Research Report. London: Health and Safety Executive books, 1998.

Beattie, J., Covey, J., Dolan, P., Hopkins, L., Jones-Lee, M., Loomes, G., Pidgeon, N., Robinson, A., Spencer, A. On the Contingent Valuation of Safety and the Safety of contingent Valuation: Part 1 - Caveat Investigator. Journal of Risk and Uncertainty 1998; 17: 5-25.

Cairns, J., van der Pol, M., Saving future lives. A comparison of three discounting models. Health Economics 1997; 6: 341-350.

Chapman, G.B. Temporal discounting and utility for health and money. Journal of Experimental Psychology 1996; 22: 771-791.

Chilton, S., Spencer A, Empirical evidence of inconsistency in Standard Gamble choices under direct and indirect elicitation methods. Swiss Journal of Economics 2001: 137: 65-86.

Diener, A., O'Brien, B., Gafni, A. Health care contingent valuation studies: A review and classification of the literature. Health Economics 1998; 7: 313-326.

Dolan, P. Modelling valuations for health states: the effect of duration. Health Policy 1996; 38: 189203.

Dolan, P., Cookson, R. A qualitative study of the extent to which health gain matters when choosing between groups of patients. Health Policy 2000; 51: 19-30.

Dolan, P., Cookson, R., Ferguson, B. Effect of discussion and deliberation on public's views about priority setting in health care: focus group study. British Medical Journal 1999; 318: 916-919.

Dolan, P., Green, C. Using the person trade-off approach to examine differences between individual and social values. Health Economics 1998; 7: 307-312.

Dolan, P., Gudex, C. Time preference, duration and health state valuations. Health Economics 1995; 4: 289-299.

Dolan, P., Jones-Lee, M. The time trade-off: A note on the effect of lifetime reallocation of consumption and discounting. Journal of Health Economics 1997; 16: 731-739.

Ericsson, K.A., Simon, H.A. Verbal reports as data. Psychological Review 1980; 87: 215-251.

Gafni, A. (1995). Time in health: can we measure individuals' "pure time preference". Medical Decision Making 1995; 15: 31-37.

Gudex, C., Dolan, P., Kind, P., Williams, A. Valuing health states: Interviews with the general public. European Journal of Public Health 1997; 7: 441-448. 
Jansen, S.J.T., Stiggelbout, A.M., Wakker, P.P, Vlieland, T.P.M.V., Leer, J.W.H., Nooy, M.A., Kievit, J. Patients' utilities for cancer treatments: a study of the chained procedure for the standard gamble time tradeoff. Medical Decision Making 1998; 18: 391-399.

Llewellyn-Thomas, H., Sutherland, H.J., Tibshirani, R., Ciampi, A., Till, J.E., Boyd, N.F. The measurement of patients' values. Medical Decision Making 1982; 2: 449-462.

Loewenstein, G., Prelec, D. Preferences for sequences of outcomes. Psychological Review 1993; 100: 91-108.

McNeil, B.J., Weichselbaum, R., Pauker, S.G. Fallacy of the five-year survival in lung cancer. New England Journal of Medicine 1978; 25: 1299-1397.

Miyamoto, J., Eraker, S. A multiplicative model of utility of survival duration and health quality. Journal of Experimental Psychology: General, 1988; 117: 3-20.

Patton, M.Q. Qualitative Evaluation and Research Methods, Sage Publications, London, 1990.

Pliskin, J.S., Shepard, D.S., Weinstein, M.C. Utility functions of life years and health status. Operational Research 1980; 28: 206-224.

Rabin, M., Thaler, R.H. Anomalies - Risk aversion, Journal of Economic Perspectives 2001; 15: 219232.

Morrison, G.C., The endowment effect and expected utility. Scottish Journal of Polictical Economy 2000; 47: 183-197.

Redelmeier, D.A., Heller, D.N. Time preference in medical decision-making and cost-effectiveness analysis. Medical Decision Making 1993; 13: 212-217.

Robinson, A., Dolan, P., Williams, A. Valuing health states using VAS and TTO: what lies behind the numbers? Social Science and Medicine 1997; 45: 1289-1297.

Sutherland, H.J., Llewellyn-Thomas, H., Boyd, N.F., Till, J.E., Attitude toward quality of survival: The concept of maximal endurable time, Medical Decision Making 1982; 2: 299-309.

Torrance, G.W., Thomas, W.H., Sackett, D.L. A utility maximization model for evaluation of health care programmes. Health Service Research 1972; 7: 118-33.

Tversky, A., Sattath, S., Slovic, P. Contingent Weighting in Judgement and Choice. Psychological Review 1988; 95: 371-384. 


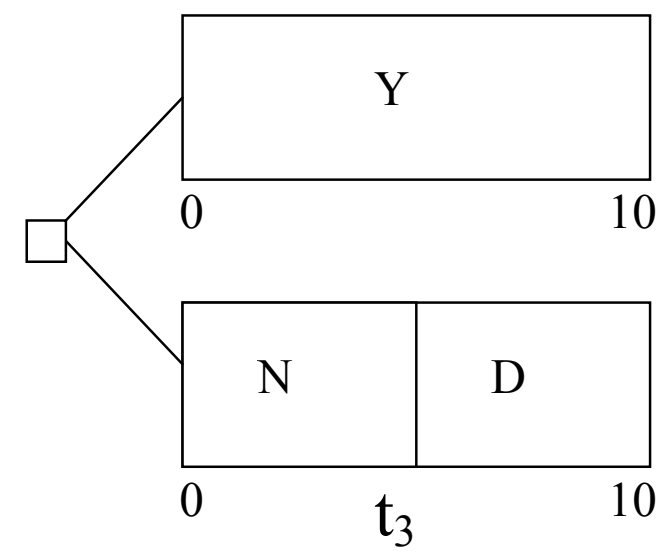

Figure 1. Question 3
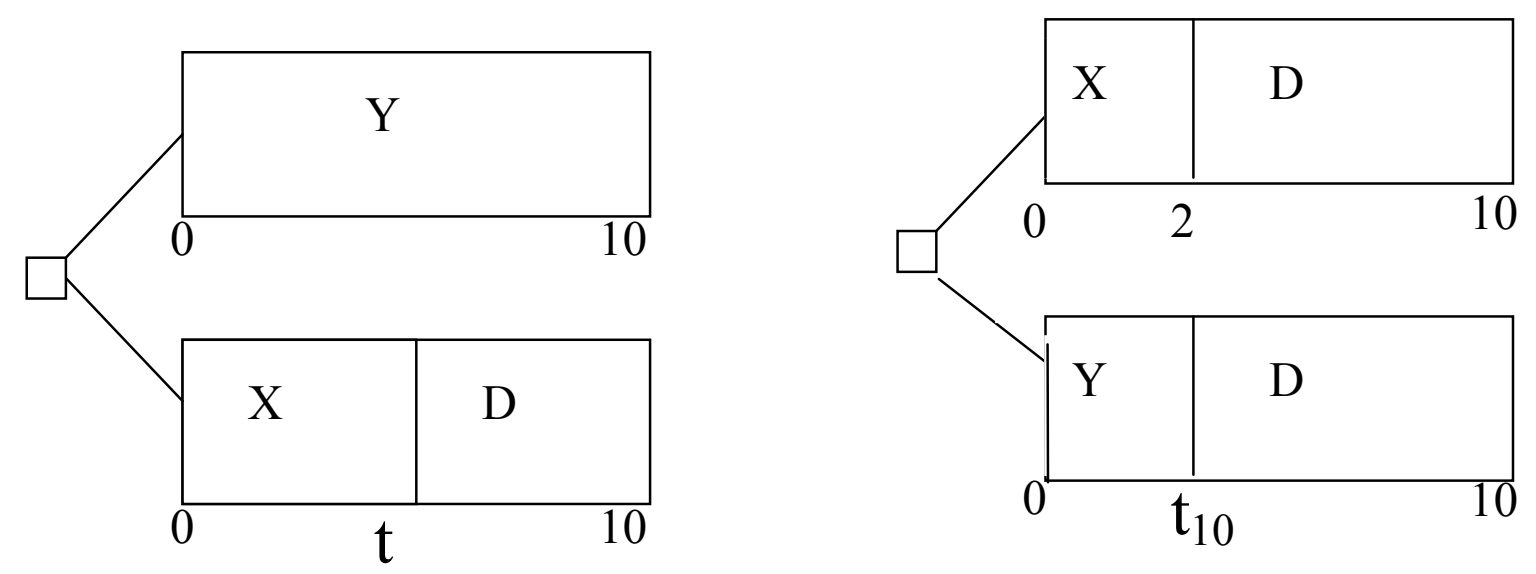

Figure 2. Example and links with question 10 
Table 1. An overview of the questionnaire

\begin{tabular}{|c|c|c|c|c|}
\hline Question & $\begin{array}{c}(1) \\
\text { Question type }\end{array}$ & $\begin{array}{c}(2) \\
\text { Health state }\end{array}$ & $\begin{array}{c}(3) \\
\text { Comparison } \\
\text { health states }\end{array}$ & $\begin{array}{c}\text { (4) } \\
\text { Abbreviation }\end{array}$ \\
\hline 1 & Conventional TTO & $\mathrm{W}$ & $\mathrm{N}+\mathrm{D}$ & $\operatorname{direct~V(W)}$ \\
\hline 2 & Conventional TTO & $\mathrm{X}$ & $\mathrm{N}+\mathrm{D}$ & $\operatorname{direct~V(X)}$ \\
\hline 3 & Conventional TTO & $\mathrm{Y}$ & $\mathrm{N}+\mathrm{D}$ & $\operatorname{direct~V(Y)}$ \\
\hline 4 & Unconventional TTO & $\mathrm{Z}$ & $\mathrm{N}+\mathrm{D}$ & $\operatorname{direct~V(Z)}$ \\
\hline 9 & Unconventional TTO & $2 \mathrm{Y}+8 \mathrm{D}$ & $\mathrm{Z}+\mathrm{D}$ & indirect V(Y) \\
\hline 10 & Unconventional TTO & $2 \mathrm{X}+8 \mathrm{D}$ & $\mathrm{Y}+\mathrm{D}$ & indirect V(X) \\
\hline
\end{tabular}

Table 2. The sample

\begin{tabular}{|l|c|c|c|}
\hline & $\begin{array}{c}(1) \\
21-39\end{array}$ & $\begin{array}{c}(2) \\
40-59\end{array}$ & $\begin{array}{c}(3) \\
\text { Total }\end{array}$ \\
\hline Male & $9(30 \%)$ & $3(10 \%)$ & $12(40 \%)$ \\
\hline Female & $8(27 \%)$ & $10(33 \%)$ & $18(60 \%)$ \\
\hline Total & 17 & 13 & 30 \\
\hline
\end{tabular}


Table 3. The summary statistics

\begin{tabular}{|c|c|c|c|c|c|}
\hline $\begin{array}{c}\text { Questio } \\
\mathrm{n}\end{array}$ & $\begin{array}{c}(1) \\
\text { Abbreviation }\end{array}$ & $\begin{array}{c}(2)^{1} \\
\mathrm{n}\end{array}$ & $\begin{array}{c}(3) \\
\text { Mean }\end{array}$ & $\begin{array}{c}(4) \\
\text { Median }\end{array}$ & $\begin{array}{c}(5) \\
\text { Standard } \\
\text { deviation }\end{array}$ \\
\hline 1 & direct $\mathrm{V}(\mathrm{W})$ & 30 & 0.802 & 0.950 & 0.248 \\
\hline 2 & direct $\mathrm{V}(\mathrm{X})$ & 30 & 0.856 & 0.900 & 0.163 \\
\hline 3 & direct $\mathrm{V}(\mathrm{Y})$ & 29 & 0.635 & 0.650 & 0.217 \\
\hline 4 & direct $\mathrm{V}(\mathrm{Z})$ & 28 & 0.457 & 0.450 & 0.207 \\
\hline 9 & indirect $\mathrm{V}(\mathrm{Y})$ & 28 & 0.748 & 0.7 & 0.594 \\
\hline 10 & indirect $\mathrm{V}(\mathrm{X})$ & 29 & 1.299 & 1.050 & 0.779 \\
\hline
\end{tabular}

${ }^{1}$ Respondents were excluded from the analysis if they felt that the health states were worse than death. Two respondents felt that health state $Z$ was worse than death and 1 respondent felt that health state Y was worse than death.

Table 4. The Wilcoxon signed ranks test

\begin{tabular}{|l|c|c|}
\hline & \multicolumn{1}{|c|}{$\begin{array}{c}(1) \\
\text { Question 9 }\end{array}$} & $\begin{array}{c}\text { (2) } \\
\text { Question 10 }\end{array}$ \\
\hline $\begin{array}{l}\text { No. of cases where } \\
\text { indirect value }>\text { direct } \\
\text { value }\end{array}$ & 14 & 20 \\
\hline $\begin{array}{l}\text { No. of cases where } \\
\text { indirect value }<\text { direct } \\
\text { value }\end{array}$ & 13 & \\
\hline $\begin{array}{l}\text { No. of cases where } \\
\text { indirect value }=\text { direct } \\
\text { value }\end{array}$ & 1 & 7 \\
\hline Total & Indirect V(X) versus direct V(X) \\
\hline & 28 & 2 \\
\hline Wilcoxon Z & accept & 29 \\
\hline 2-tailed P & -0.01201 & reject \\
\hline & 0.9044 & -3.3395 \\
\hline
\end{tabular}


Table 5. The direct and indirect value for health state $\mathrm{Y}$

\begin{tabular}{|l|c|c|c|c|}
\hline \multicolumn{5}{|c|}{ Question 9 } \\
\hline & $\begin{array}{c}(1) \\
\text { indirect }> \\
\text { direct }\end{array}$ & $\begin{array}{c}(2) \\
\text { indirect }< \\
\text { direct }\end{array}$ & $\begin{array}{c}(3) \\
\text { indirect } \\
\text { direct }\end{array}$ & $\begin{array}{c}(4) \\
(\mathrm{n}=28)\end{array}$ \\
\hline $\begin{array}{l}\text { Willing to trade-off quality for } \\
\text { longevity of life }\end{array}$ & 13 & 0 & 0 & 13 \\
\hline $\begin{array}{l}\text { Unwilling to prolong time in a } \\
\text { lower quality of life }\end{array}$ & 0 & 10 & 1 & 11 \\
\hline $\begin{array}{l}\text { Increase longevity of life } \\
\text { irrespective of quality of life }\end{array}$ & 0 & 3 & 0 & 3 \\
\hline $\begin{array}{l}\text { Health states perceived to be the } \\
\text { same }\end{array}$ & 0 & 0 & 0 & 0 \\
\hline $\begin{array}{l}\text { Demanding more time in lower } \\
\text { quality of life }\end{array}$ & 1 & 0 & 0 & 1 \\
\hline
\end{tabular}

Table 6. The direct and indirect value for health state $\mathrm{X}$

\begin{tabular}{|l|c|c|c|c|}
\hline \multicolumn{5}{|c|}{ Question 10 } \\
\hline & $\begin{array}{c}(1) \\
\text { indirect }> \\
\text { direct }\end{array}$ & $\begin{array}{c}(2) \\
\text { indirect }< \\
\text { direct }\end{array}$ & $\begin{array}{c}(3) \\
\text { indirect }=\text { direct }\end{array}$ & $\begin{array}{c}(4) \\
(\mathrm{n}=29)\end{array}$ \\
\hline $\begin{array}{l}\text { Willing to trade-off quality for } \\
\text { longevity of life }\end{array}$ & 20 & 1 & 0 & 21 \\
\hline $\begin{array}{l}\text { Unwilling to prolong time in } \\
\text { lower quality of life }\end{array}$ & 0 & 3 & 0 & 3 \\
\hline $\begin{array}{l}\text { Increase longevity of life } \\
\text { irrespective of quality of life }\end{array}$ & 0 & 1 & 2 & 3 \\
\hline $\begin{array}{l}\text { Health states perceived to be the } \\
\text { same }\end{array}$ & 0 & 1 & 0 & 1 \\
\hline $\begin{array}{l}\text { Demanding more time in lower } \\
\text { quality of life }\end{array}$ & 1 & 0 & 0 & 1 \\
\hline
\end{tabular}

Table 7. Summary of predicted impacts

\begin{tabular}{|l|c|}
\hline & predicted impacts \\
\hline Disproportionate concern for quality of life & + \\
\hline Time preference & + \\
\hline Disproportionate concern for longevity of life & - \\
\hline Maximal endurable time & - \\
\hline
\end{tabular}




\section{Q Queen Mary \\ University of London}

This working paper has been produced by the Department of Economics at Queen Mary, University of London

Copyright ( 2001 Anne Spencer All rights reserved.

\section{Department of Economics}

Queen Mary, University of London

Mile End Road

London E1 4NS

Tel: +44 (0)20 78825096 or Fax: +44 (0)20 89833580

Email: j.conner@qmw.ac.uk

Website: www.econ.qmw.ac.uk/papers/wp.htm 